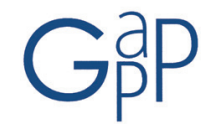

GESTIÓN Y ANÁLISIS DE POLÍTICAS PÚBLICAS, Nueva Época, nº 13 enero-junio 2015 ISSN: 1989-8991

DOI: http://dx.doi.org/10.24965/gapp.voi13.10231

\title{
Estudio de casos y propuestas jurídicas para el ejercicio de la potestad sancionadora en los centros educativos
}

\author{
Alfonso Conejo Rodríguez \\ Ministerio Educación Cultura y Deporte. Dirección Provincial de Ceuto \\ alfonso.conejo@ceuta.mecd.es
}

Resumen

Existen múltiples investigaciones relacionadas con la violencia escolar, la mayoría tratando aspectos psicosociales y educativos. Sin embargo, faltan trabajos que aborden los aspectos administrativos y legales.

Este artículo forma parte de una investigación más extensa, que comienza con una revisión del marco legislativo, y en la cual se comprobaron los aspectos que merecen mayor atención y las posibles causas del incumplimiento de las normas. El análisis documental de partes disciplinarios y expedientes sancionadores ponen de manifiesto la existencia de múltiples errores en la tramitación. Cuando los centros educativos tienen que adoptar medidas sancionadoras, es importante que el procedimiento no quede invalidado o pueda ser denunciado en los tribunales de justicia. Un cuestionario aplicado a los profesores, reveló que se sienten poco preparados para desempeñar esta función.

A partir de los resultados obtenidos, se sugiere abordar la necesaria adaptación de la documentación elaborada en función de su autonomía, con la participación de todos los sectores de la comunidad educativa, y concretar aquellos aspectos que hagan del centro un lugar de convivencia, optimizando recursos en el marco de la legislación. Finalmente, se ofrecen conclusiones relacionadas con la necesidad de facilitar a los centros protocolos de actuación, y abordar procesos específicos de formación del profesorado.

Palabras clave

Conflicto, violencia escolar, convivencia escolar, disciplina.

\section{Case studies and legal proposals to the excercise of the legal authority in the schools}

\section{Abstract}

There are numerous investigations related to school violence, most of them are about psychosocial and educational aspects. Nevertheless, there are not enough articles that tackle administrative and legal aspects.

This article is part of a more extensive research, which begins with a revision of the legal framework, and in which the aspects which require more attention and the possible causes of non-compliance with the rules have been verified. The documentary analysis of the disciplinary reports and sanction files in a high school, show the existence of numerous errors in the procedure. When schools must adopt sanctioning measures it is important that the procedure is not invalidated or denounced in the courts of justice. A survey that was answered by the teachers revealed that they do not feel qualified perform this function.

From the results obtained we suggest carrying out the adaptation of the school internal regulations in the course of its duties with the participation of all sectors of the educational community, and to make specific those aspects which made the education centre a coexistence place, optimizing the resources within the legislative framework. Finally, conclusions related to the necessity to facilitate the schools protocols of action and to address specific teacher training processes are offered.

\section{Key words}

Conflict, school violence, scholastic coexistence, discipline. 


\section{INTRODUCCIÓN}

Gestionar con calidad es uno de los retos al que se enfrentan las organizaciones públicas. Entre estas se incluyen los centros docentes, con el compromiso de toda la comunidad educativa, sobre todo entre dirección y personal, para la mejora permanente de los procesos y la evaluación continua. Este artículo presenta parte de una investigación1 centrada en el diagnóstico de la convivencia escolar, la identificación de áreas de mejora, así como la planificación, puesta en marcha, y evaluación de actuaciones que aseguren informaciones válidas en torno a su eficiencia. Aunque el verdadero valor procede de la coherencia de la cadena argumental y el marco final, debe constituir un fin principal detectar la metodología que mejores respuestas dé a las dificultades que se plantean en la práctica diaria docente, así como los puntos positivos con el fin de ampliar y perfeccionar su aplicación. La escuela es hoy, una organización que aprende y cambia, y es muy importante acertar con su misión, sus fines y objetivos (Villa, 2009).

El carácter de la investigación realizada es fundamentalmente evaluativo e instrumental, lo que hace sus objetivos limitados, pero facilita que los resultados puedan servir para profundizar en aspectos administrativos del procedimiento sancionador, y favorecer la elaboración de protocolos de actuación aplicables en centros educativos, sin olvidar la información que puede aportar de cara al diseño de programas de formación que capaciten al profesorado para la instrucción de expedientes sancionadores. Pero el verdadero reto es establecer procesos de revisión en la organización y gestión de las instituciones educativas, así como descubrir la incidencia de los factores educativos, organizativos y procesales en los problemas de convivencia.

La autonomía escolar, en relación con la calidad de la enseñanza, tiene sentido si se potencia para el desarrollo de los centros docentes, no solo buscando su correspondencia con el rendimiento del alumnado. Se trata de hallar la vinculación entre la mejora de la convivencia y la capacidad de autorregulación y participación del colectivo docente, resultando decisivo el mecanismo por el que se articula, sobre todo a través de la elaboración de planes de convivencia.

\section{FUNDAMENTOS DE LA POTESTAD SANCIONADORA EN LOS CENTROS DOCENTES}

Vivimos en una sociedad nueva, porque se han producido cambios en el tejido social, que afectan a las relaciones (Binaburo, Itúrbide y Muñoz-Maya, 2007). En la búsqueda de soluciones a los problemas de convivencia, la potestad sancionadora constituye una de las prerrogativas de los centros docentes, partiendo de un código, siguiendo el proceso legalmente previsto y utilizando medidas de gradación razonables.

Sin embargo, para comprender en toda su dimensión el razonamiento ideal de convivencia, es necesario examinar la orientación de las normas, qué actitudes promueven y qué pueden lograr, situando cada precepto desde la evolución socio legal de la enseñanza; $Y$ no solo referirnos a la normativa educativa específica, sino a todo el ordenamiento administrativo español desde la Constitución de 1978 con especial atención a la Ley 30/1992, de 26 de noviembre, de Régimen Jurídico de las Administraciones Públicas y del Procedimiento Administrativo Común que consagra los distintos principios en la materia, incluir la normativa sobre menores, las recomendaciones de distintos organismos, tratados internacionales, así como la legislación europea.

También es nuestra obligación conocer los remedios que aplica la jurisprudencia contencioso-administrativa, y en especial el Tribunal Supremo, frente a la vulneración de derechos fundamentales, aunque la restauración de los mismos a veces no es viable, en la mayoría de los casos resulta tardía, y en otros el demandante solo consigue la sentencia declarativa, tal como recuerda la Audiencia provincial de Cuenca en su Sentencia de 22 de marzo de 2001 (Cabezudo, 2008: 37).

También informa la cuestión la distinta normativa autonómica, desembocando en la aplicable en el ámbito territorial en el que desarrollamos nuestro estudio, al que pertenecen Ceuta, Melilla, y los centros en el extranjero, donde apenas se han producido modificaciones normativas (continua en vigor el Real Decreto 732/1995 de derechos y deberes de los alumnos), por lo que constituye un banco de pruebas inmejorable para estudiar las variables que hacen que los centros evolucionen en función a su autonomía.

Completando lo anterior tenemos la autorregulación de los centros docentes, dotándose de documentos y mecanismos para el despliegue de la institución con el objetivo, entre otros, de mejorar la gobernabilidad. Su

1 Tesis doctoral: “Disciplina y convivencia en centros de Secundaria. El procedimiento sancionador en los IES de Ceuta”. Universidad de Granada. Facultad de Educación y Humanidades. Departamento de Didáctica y Organización Escolar. 
premisa y herramienta de gestión es la participación, fomentando la toma de decisiones colegiadas, y teniendo en cuenta que en la posibilidad de que los centros dicten sus normas es donde aparecen matices.

La potestad sancionadora de la Administración pública es reconocida constitucionalmente (artículo 25.1 Constitución Española). Pero no toda trasgresión jurídico-administrativa da lugar automáticamente a sanción, sino sólo aquellas tipificadas como tales y para las que se prevé la penalidad correspondiente. Asimismo, para que el órgano que conoce de un procedimiento sancionador -como cualquier procedimiento administrativo- pueda decidir la cuestión que se plantea, es necesario que concurran todos los requisitos que el ordenamiento establece y haberse seguido el procedimiento legalmente previsto; Si se dictara resolución sin respetar alguno incurriría en infracción del ordenamiento jurídico (por ejemplo no contener el acto de iniciación los extremos recogidos en el artículo 13.1 del Reglamento de Procedimiento para el ejercicio de la Potestad Sancionadora), pues no estamos ante requisitos puramente procedimentales -determinantes de inadmisibilidad-, sino para ejercer válidamente la potestad sancionadora. Y aunque no es necesario que los reglamentos de las instituciones educativas establezcan la exacta determinación de los supuestos que den lugar a la iniciación del expediente, desde luego debe evitarse la discrecionalidad con una adecuada motivación.

En cualquier caso, los que conocemos la práctica en centros educativos de cierta conflictividad, no podemos pasar por alto que una traslación sin matices de las garantías de publicidad y procesales del ámbito penal, o incluso del administrativo sancionador, puede parecer indeseable. La adaptación de la actividad docente a la jurisprudencia vigente debe ser mesurada, y en términos globales contenida, con detallada consideración de las notabilísimas diferencias en cuanto a principios jurídicos subyacentes, a dimensión social de las conductas, y a relevancia social de las alternativas que hay entre los distintos instrumentos de sanción.

La Ley Orgánica 2/2006 de 3 de mayo de Educación, que recoge la derogación expresa de la LOGSE, de la LOPEGCE y de la LOCE, incluye referencias continuas en su articulado a la convivencia, otorgándole importancia capital en el bienestar y desarrollo de los miembros de la comunidad y para el rendimiento del alumnado, lo que se evidencia en la agilización de los procedimientos para la resolución de conflictos, la prescripción de un plan de convivencia, y en que define en cada etapa los objetivos y las funciones de cada órgano de gestión del centro en relación a ella. En su artículo 124, en cumplimiento de las disposiciones generales sobre autonomía de los centros, establece que estos elaborarán las normas de organización y funcionamiento, incluyendo las que garanticen el plan de convivencia y su cumplimiento, debiendo facilitarlo las administraciones educativas.

Con la reforma operada por la Ley Orgánica 8/2013, de 9 de diciembre, para la mejora de la calidad educativa, se refuerza el citado artículo 124 estableciendo que el plan de convivencia se incorporará a la programación general anual, recogerá todas las actividades que se programen para fomentar un buen clima de convivencia, concretará derechos, deberes y medidas correctoras en caso de incumplimiento con arreglo a la normativa, tomando en consideración la situación y condiciones de alumnos y alumnas, e incluirá actuaciones para la resolución de conflictos, prevención de violencia de género, igualdad y no discriminación. Las normas de convivencia de los centros serán de obligado cumplimiento y las correcciones tendrán carácter educativo, recuperador y proporcional a las faltas cometidas. Las conductas que atenten contra la dignidad personal de otros miembros de la comunidad educativa, que tengan como origen o consecuencia una discriminación o acoso basado en el género, orientación o identidad sexual, racial, étnico, religioso, de creencias o de discapacidad, o que se realicen contra el alumnado más vulnerable, tendrán la calificación de falta muy grave y conllevarán la expulsión, temporal o definitiva del centro. Las medidas correctoras por la comisión de faltas leves serán inmediatamente ejecutivas. Por último, incluye que los miembros del equipo directivo y los profesores y profesoras serán considerados autoridad pública, y los hechos constatados por ellos tendrán valor probatorio y disfrutarán de presunción de veracidad «iuris tantum» o salvo prueba en contrario, sin perjuicio de las pruebas que, en defensa de los respectivos derechos o intereses, puedan señalar o aportar los propios alumnos y alumnas.

Fruto de lo anterior, los centros educativos elaborarán al principio de cada curso una programación general anual, que recoja las normas y todos los planes de actuación acordados y aprobados (artículo 125 LOE). Y es que el énfasis de la LOMCE en poner de manifiesto el principal problema de los centros educativos actualmente, ya se puede vislumbrar con la nueva redacción del artículo 1, donde se configuran los principios en los que se inspira el sistema educativo español, sobre todo en el apartado k) que queda en los siguientes términos: La educación para la prevención de conflictos y la resolución pacífica de los mismos, así como para la no violencia en todos los ámbitos de la vida personal, familiar y social, y en especial en el del acoso escolar.

Donde no se encuentra variación es en las competencias del Director en cuanto a la convivencia en el centro, el cual debe garantizar la mediación, resolver los conflictos e imponer las medidas disciplinarias a alumnos 
(artículo 132 f), mientras el Consejo Escolar conocerá de la resolución de conflictos disciplinarios, velará por que se atengan a la normativa vigente, y cuando las medidas disciplinarias adoptadas por el Director correspondan a conductas que perjudiquen gravemente la convivencia del centro, a instancia de padres, madres o tutores legales, podrá revisar la decisión adoptada y proponer, en su caso, las medidas oportunas (artículo 127 f).

Incidiendo en esta línea, la LOMCE introduce entre las funciones del Consejo Escolar recogidas en el artículo $127 \mathrm{~g}$ de la LOE (proponer medidas e iniciativas que favorezcan la convivencia en el centro, la igualdad entre hombres y mujeres y la resolución pacífica de conflictos), la igualdad de trato y la no discriminación, por las causas a las que se refiere su propio artículo 84.3, y la prevención de la violencia de género.

Sin embargo, por experiencias anteriores sabemos que los cambios en las rutinas escolares no se producen a toque de ley, y que en todo caso se consigue un cambio cosmético, no en el fondo de las cosas. Los cambios son reales cuando el colectivo docente toma conciencia y siente su necesidad, inicia un proceso de reflexión y comienza a modificar su práctica.

Precisamente la inquietud por la convivencia en los centros educativos no es algo nuevo, pues ya en el Reglamento Orgánico de los Centros de Secundaria (R.D. 83/1996) se regulaba entre las comisiones que funcionan en el Consejo Escolar la de convivencia, constituida en la forma que determine el reglamento de régimen interior del centro, y cuyas competencias estaban especificadas en este. $Y$ es que en los últimos años, el Consejo Escolar del Estado $(2005,401)^{2}$, venía recomendando a las administraciones educativas que establecieran un marco jurídico que mejorara la gobernabilidad de los centros, que destinaran todos los medios y recursos necesarios para fomentar la convivencia y que establecieran mecanismos que permitan una mayor implicación de las familias y los distintos sectores educativos.

$Y$ aunque podemos concluir que el modelo participativo se ha consolidado, fomentando la toma de decisiones por órganos colegiados, una idea emerge del marco legislativo analizado: A pesar de que el centro disponga de un ámbito importante de libre autoorganización de sus actividades, funcionamiento y disciplina internos, sus decisiones en esta materia no son enteramente libres e incondicionadas, no pueden sustraerse por entero a pautas externas de contraste y enjuiciamiento, como ha reconocido la jurisprudencia del Tribunal Constitucional y la del Supremo.

Sirva de ejemplo la sentencia del T. S. de 9/12/2003 que enjuiciaba un caso de expulsión arbitraria (el calificativo es del propio Tribunal), de un alumno adolescente por parte de un centro escolar. La sentencia recaída plantea como fundamentos jurídicos, que la falta de información puntual al interesado o a sus padres acerca de los cargos imputados y de la persona del instructor, o la falta de audiencia, o la falta de contradicción probatoria durante la instrucción del expediente, son motivos para considerar que se vulneran principios Constitucionales (artículos 24,25 y 27 C.E.), imprescindibles en la tramitación del expediente. Y el remedio escogido para reaccionar frente a vulneración de derechos constitucionales fue la indemnización del daño moral padecido por el propio alumno y por sus padres.

\section{3.- DIAGNÓSTICO DE LA CONFLICTIVIDAD}

Al inicio de nuestro trabajo y como paso previo para el diseño de actividades, se llevó a cabo un diagnóstico de la situación, a través de evaluaciones, cuestionarios, entrevistas y encuestas.

Se incluyó la opinión de los alumnos sobre aspectos que pueden informar la situación: sobre una muestra de ambos ciclos de ESO, se indagó en relación a las normas de convivencia, sobre la determinación del conocimiento que los alumnos tienen de las normas, su participación en la elaboración de las mismas, la finalidad que le atribuyen, y el su grado de cumplimiento. Destacan dos tipos de conclusiones: De un lado, la gran mayoría declara

2 Entre las múltiples recomendaciones que el Consejo Escolar del Estado ha venido realizando a través de los Informes sobre el estado y situación del sistema educativo y las correspondientes propuestas de mejora cabe señalar las siguientes:

- $\quad$ Se hacen imprescindibles mejoras (legislativas, curriculares, organizativas, de formación del profesorado) y también, propuestas de colaboración familia-escuela para situaciones que requieran de esa colaboración y propuestas en el ámbito comunitario (asistenciales, orientación, vigilancia). (2008, 134).

- Asimismo, se hace un llamamiento al Ministerio de Educación y a la Conferencia Sectorial de Educación, para el desarrollo de un nuevo marco de derechos, deberes y garantías de los y las estudiantes y el establecimiento de unos criterios comunes en el tratamiento de la convivencia escolar $(2009,181)$.

- $\quad$ Se insta al Ministerio de Educación a que promulgue un Real Decreto que actualice el de 1995 sobre derechos y deberes del alumnado, que se adapte al actual sistema educativo y sea un marco común para todo el alumnado. Además se propone la revisión de las normativas sobre convivencia y el impacto de las buenas prácticas (2010, 22). 
conocer las normas de convivencia, que estas son necesarias, aclaran lo que está permitido y lo que no, y reconocen su valor educativo al estar diseñadas más para prevenir que para castigar; De otro, la mayoría considera que las normas de convivencia no son justas, los profesores no colaboran para conseguir su cumplimiento, y que los alumnos han participado poco en su elaboración.

El estudio de casos, así como el análisis de los partes disciplinarios y el proceso de tramitación de los expedientes sancionadores, sirvieron para identificar las variables, los indicadores que explicitan el clima de conflictividad, rediseñar y volver a planificar el resto de actuaciones. Durante tres cursos académicos consecutivos se llegaron a analizar 2927 partes disciplinarios por conductas de los alumnos consideradas contrarias a las normas de convivencia y, simultáneamente, se abordó el análisis de los expedientes sancionadores a los que dieron lugar.

Descubrimos que el nivel de conflictividad aumenta en el segundo trimestre, especialmente en febrero. Es superior a partir de la cuarta hora lectiva, apareciendo la quinta hora como muy conflictiva. Se localiza en los primeros cursos de la ESO, siendo un colectivo de alto riesgo los alumnos repetidores de primero o segundo que ya habían repetido un curso en primaria.

El principal problema son las conductas disruptivas, concretadas en falta de respeto y desinterés. Las conductas mas frecuentes la constituyen perturbar el normal desarrollo de actividades de clase, impedir o dificultar el estudio a sus compañeros, faltas de puntualidad y asistencia. El resto de comportamientos nos son considerados por el profesorado como frecuentes. Existe un bajo índice de injurias, agresiones y amenazas, siendo las menos frecuentes las actuaciones perjudiciales para la salud e integridad, así como la suplantación de personalidad y la falsificación o sustracción de documentos académicos.

La iniciativa a la hora de iniciar el procedimiento disciplinario es de los profesores, y la reacción más frecuente ante una conducta antisocial es formular un parte disciplinario. Pocos profesores acumulan muchos partes, y un grupo reducido de alumnos los que los reciben, lo que se manifiesta en una elevada reincidencia. Las conductas en las que el profesorado preferentemente opta por imponer partes son la agresión, seguida por los actos de indisciplina, injuria, amenaza u ofensas graves. Las que son en menor grado merecedoras de parte son las faltas de puntualidad, impedir el estudio a compañeros, y perturbación de actividades de clase.

Pero lo que mas nos interesa, en relación al planteamiento del presente artículo, es que existen deficiencias en la organización y en los procesos, que redundan en la falta de concreción de los criterios a la hora de actuar frente a un conflicto. Un alto porcentaje de partes no dan lugar a expedientes ni actuación alguna, es decir quedan impunes, la mayoría de las veces por deficiente organización administrativa. Asimismo, por falta de formación jurídica del instructor y deficiencias en la tramitación, se detectan graves y numerosos errores de técnica jurídica, sobre todo el acto de iniciación, tipificación, plazos, y aplicación de reiteración, reincidencia, atenuantes y acentuantes.

En el momento de concretar la sanción, también se encuentran carencias, pues en la mayoría de los casos se aplican sanciones represivas, combinadas con alguna recuperadora, nunca coercitivas; No se deriva responsabilidad civil o penal, ni se reacciona a la falta de cumplimiento de la sanción, o ante el incumplimiento de medidas cautelares.

\section{4.- ACTUACIÓN ANTE LOS CONFLICTOS DE CONVIVENCIA}

La aplicación de un cuestionario a profesores, nos enseñó como actúan ante situaciones de indisciplina escolar: El profesorado califica como gravemente perjudiciales para la convivencia todas las conductas descritas en la normativa vigente, excepto la falta de puntualidad y asistencia. Todos consideran grave la agresión y la gran mayoría dirigirse a otro alumno o al profesor de forma despectiva, maleducada, grosera o desafiante... (A pesar de ser considerada leve en la normativa), así como la reiteración de conductas. Le siguen la suplantación de personalidad, la falsificación de documentos, y el incumplimiento de sanciones.

Los profesores que han sido instructores de expedientes sancionadores califican con más severidad las conductas graves, y estiman que se dan con más frecuencia. Los varones tienen una percepción inferior de la frecuencia de las conductas contrarias a la convivencia y las localizan en las aulas, se refieren a los daños materiales más generalizados y graves, acentúan la gravedad en actuaciones concretas contra los individuos, la integridad personal, a través de ofensas o amenazas, y aparecen con una actitud contraria a que los desestimen a través de incumplimiento de sanciones o suplantación de personalidad; mientras las profesoras entienden que se dan con mas frecuencia y las localizan en la totalidad del centro, concretan los daños materiales en las instalaciones del centro, consideran mas graves las actuaciones contra el grupo, como impedir el estudio, perturbar la clase, faltas de puntualidad, e incluso destaca que no aluden al insulto individual. Los profesores con una experiencia entre 13 
y 20 años, soportan mejor las situaciones conflictivas que los que cuentan con experiencia inferior o superior. Los noveles son más sensibles a conductas leves, mientras los de más de 20 años son más sensibles a las conductas graves.

Se confirmó que, generalmente, desconocen como actuar correctamente en un procedimiento sancionador, e incluso la experiencia como instructor no varia el conocimiento o aplicación del mismo, teniendo en cuenta que los errores cometidos en su tramitación pueden desembocar en la nulidad de las actuaciones.

\section{5.- INICIO E INSTRUCCIÓN DE LOS EXPEDIENTES SANCIONADORES}

La denuncia de un acto contrario a la convivencia escolar (lo que en términos coloquiales se conoce como "poner un parte") no siempre desemboca en la apertura de un expediente sancionador. Por este motivo, no todos los profesores consideran que se deba comunicar a los padres padres, ni tampoco existe unanimidad a la hora de señalar quién debería hacerlo.

\section{GRÁFICO 1. CUÁNDO NOTIFICAR A LOS PADRES}

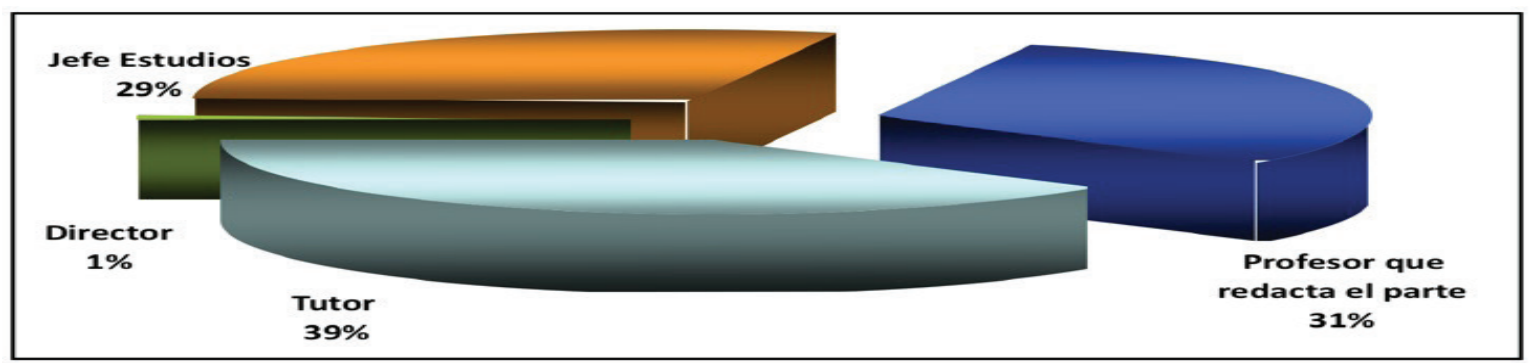

Fuente propia

GRÁFICO 2. QUIÉN DEBE NOTIFICAR A LOS PADRES

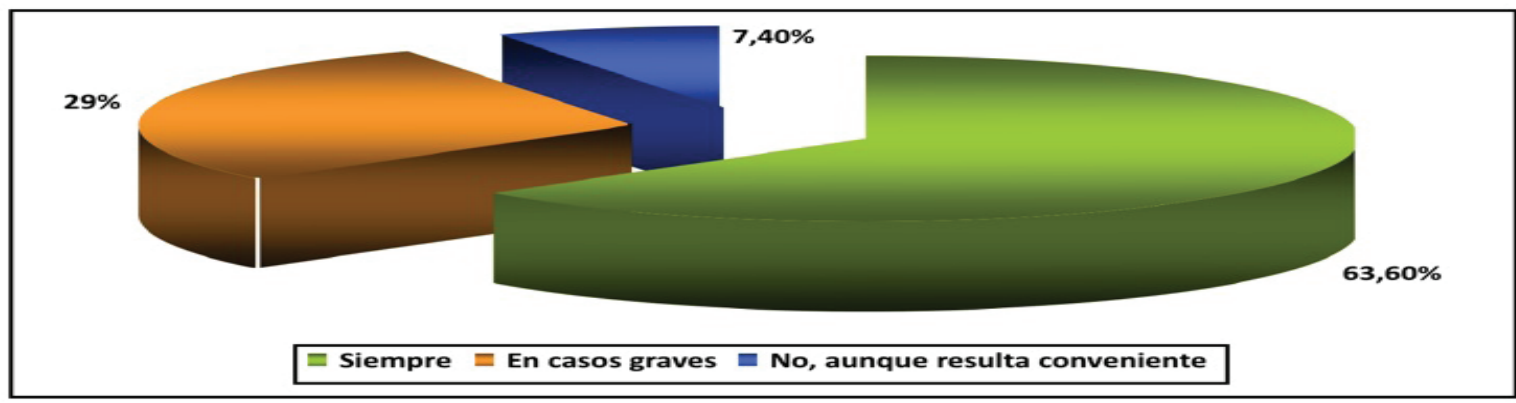

Fuente propia

GRÁFICO 3. CONOCIMIENTO DE LOS CONTENIDOS MÍNIMOS DEL ESCRITO DE INICIACIÓN
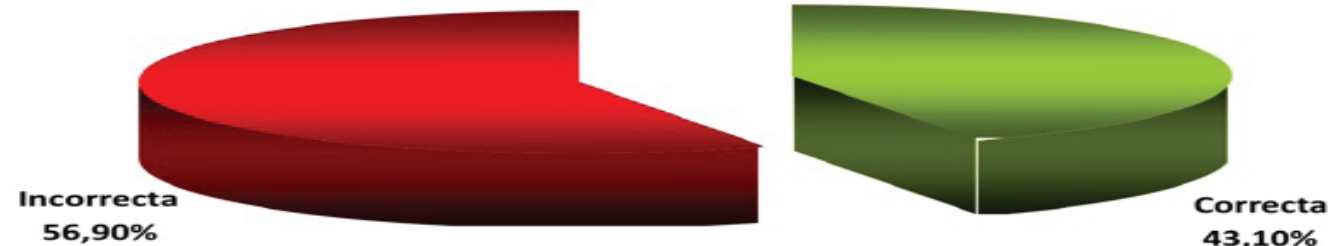

$56,90 \%$

$43,10 \%$

Fuente propia

Algo menos de la mitad conoce el contenido mínimo del documento de iniciación. 
Sobre la comunicación al servicio de inspección, el 37,4 \% elige correctamente:

GRÁFICO 4. COMUNICACIÓN AL SERVICIO DE INSPECCIÓN

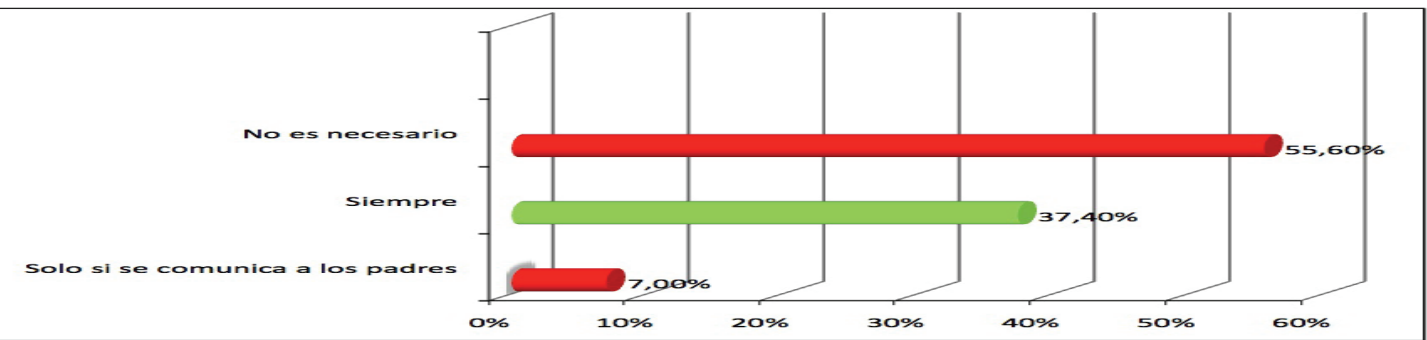

Fuente propia

Escasos porcentajes de acierto, en cuanto a las actuaciones incorrectas que suelen darse en la incoación de expedientes sancionadores:

TABLA 1. CONOCIMIENTO DE LA INCORRECCIÓN DE DETERMINADAS ACTUACIONES

\begin{tabular}{|l|c|}
\hline ACTUACIONES INCORRECTAS & ACIERTOS \\
\hline Incluir varias conductas en el mismo expediente & $23,2 \%$ \\
\hline Incoar expediente por “acumulación de faltas graves". & $3,1 \%$ \\
\hline Incoar expediente por "faltas graves reiteradas". & $3,1 \%$ \\
\hline Incoar expediente por "reiteración de faltas de respeto". & $7,2 \%$ \\
\hline Incoar por "acumulación de sanciones y reiteración de faltas". & $10,3 \%$ \\
\hline Incoar por "faltas leves con reiteración, se incluyen faltas graves". & $17,5 \%$ \\
\hline Incoar por "faltas injustificadas a clase y reiteradas faltas de disciplina". & $18,6 \%$ \\
\hline
\end{tabular}

Fuente propia

Ante la calificación incorrecta de la falta, el instructor debe proponer su archivo y solicitar la apertura de uno. Algo más de la mitad se decanta por esta opción.

GRÁFICO 5. ACTUACIÓN ANTE CALIFICACIÓN INCORRECTA

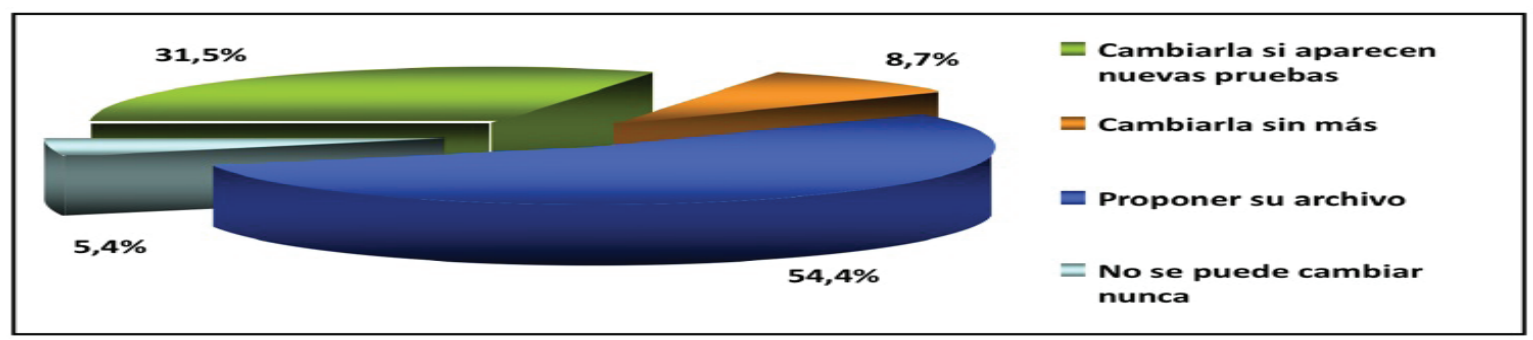

Fuente propia

Un porcentaje minoritario conoce que en caso de incumplimiento de medidas cautelares, procede es la apertura de otro expediente nuevo.

\section{GRÁFICO 6. ACTUACIÓN ANTE INCUMPLIMIENTO DE LAS MEDIDAS CAUTELARES}

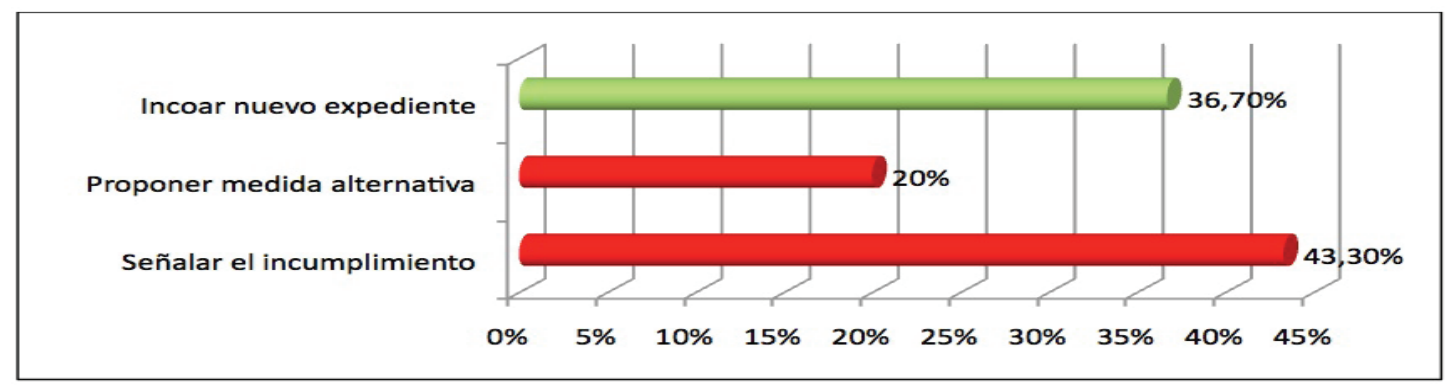

Fuente propia

GESTIÓN Y ANÁLISIS DE POLÍTICAS PÚBLICAS, Nueva Época, no 13 enero-junio 2015 - ISSN: 1989-8991 - DOI: 10.24965/gapp.v0i13.10231 
En cuanto a los errores más frecuentes que se suelen cometer en la instrucción, se revela desacierto en algunos aspectos.

TABLA 2. GRADO DE ACUERDO SOBRE LA CORRECCIÓN DE DETERMINADAS ACTUACIONES

\begin{tabular}{|l|r|r||}
\hline ACTUACIONES CORRECTAS & ACUERDO & DESACUERDO \\
\hline $\begin{array}{l}\text { Es necesario tener en cuenta la situación personal del alumno durante la } \\
\text { instrucción del expediente }\end{array}$ & $53,8 \%$ & $46,2 \%$ \\
\hline $\begin{array}{l}\text { La instrucción debe llevarse a cabo en 7 días desde la iniciación del pro- } \\
\text { cedimiento }\end{array}$ & $63 \%$ & $37 \%$ \\
\hline La resolución debe llevarse a cabo en un mes desde la comisión de la falta & $29,5 \%$ & $70,5 \%$ \\
\hline Es necesario incluir pie de recurso en la resolución & $60,2 \%$ & $39,8 \%$ \\
\hline
\end{tabular}

Fuente propia

TABLA 3. GRADO DE DESACUERDO SOBRE LA INCORRECCIÓN DE ACTUACIONES

\begin{tabular}{|l|c|r|}
\hline ACTUACIONES INCORRECTAS & ACUERDO & DESACUERDO \\
\hline $\begin{array}{l}\text { La reiteración es una circunstancia modificativa que puede agravar la culpa- } \\
\text { bilidad }\end{array}$ & $89,3 \%$ & $10,8 \%$ \\
\hline $\begin{array}{l}\text { Puede sancionarse si no consta en el expediente el parte que lo motiva ni } \\
\text { otro tipo de prueba }\end{array}$ & $27,5 \%$ & $72,4 \%$ \\
\hline Puede castigarse doblemente por el mismo acto & $32,7 \%$ & $67,3 \%$ \\
\hline
\end{tabular}

\section{CONSIDERACIONES Y RECOMENDACIONES}

A la vista de los resultados de la investigación realizada, podemos señalar que los expedientes sancionadores que se han venido tramitando en los centros analizados, adolecen de múltiples defectos en las diferentes fases del proceso. Los más destacados son:

- Gran cantidad de conductas que podrían ser merecedoras de sanción, ni siquiera motivan el inicio de expediente, o quedan impunes por deficiente organización.

- El acto de iniciación y la tipificación de la falta, no se realizan correctamente.

- Se incoa un mismo expediente por distintas faltas graves, reiteración de leves, por actos ajenos, por encubrimiento, o se califica por el resultado.

- Iniciada la instrucción no se suelen cumplir los plazos, y en muy pocos casos se incluyen pruebas indubitadas.

- Atenuantes o "acentuantes" se aplican en pocas ocasiones y de forma incorrecta.

- En la mayoría se aplican sanciones represivas, combinadas con alguna recuperadora (cambio de centro o grupo), nunca coercitivas (reparar el daño causado). No se deriva responsabilidad civil ni penal, aunque haya daños al material o instalaciones.

Por otra parte, hemos comprobado que la mayoría del profesorado que tendrá que actuar como instructor de un expediente sancionador, carece de la formación necesaria para desempeñar esta función. Todo ello nos lleva a formular las siguientes recomendaciones:

- Resulta conveniente contar con un protocolo de actuación, que sirva de guía a los centros y profesores en la tramitación de los expedientes disciplinarios.

- Es necesario diseñar y llevar a cabo actividades específicas de formación, para que los profesores puedan desempeñar adecuadamente el papel de instructor.

- Se deberían unificar los criterios disciplinarios de los profesores, para evitar situaciones de agravio.

- Se debe promover la normalización de los expedientes sancionadores, y mayor agilidad en su tramitación.

El marco normativo actual, conformado en su base por la Ley Orgánica 2/2006 de 3 de mayo de Educación y por la Ley Orgánica 8/2013 de 9 de diciembre, para la mejora de la calidad educativa, constituye una oportunidad 
sin precedentes para abordar el desarrollo reglamentario que corresponde, acorde con las necesidades que se plantean en relación con la convivencia en nuestras instituciones educativas.

Pero sin olvidar lo expresado en el párrafo anterior, y teniendo en cuenta que queda mucho camino por recorrer en la mejora de los procedimientos aplicables en los centros educativos, nuestro artículo informa sobre el margen de actuación que poseen en el marco de su autonomía, fijando su atención en las variables internas, por ser las que pueden asegurar la efectividad de su trabajo, e indica que existen formas de proceder que les permiten abordar la convivencia en las mejores condiciones, independientemente de su entorno.

\section{BIBLIOGRAFÍA}

\section{Referencias doctrinales}

Binaburo, J.A., Itúrbide, A. y Muñoz-Maya, B. (2007): Educar desde el conflicto (Madrid. CEAC).

Cabezudo Rodas, J. (2008): El juez en el colegio. (Badajoz, Ed. @becedario).

Consejo Escolar del Estado (2005): Informe sobre el estado y situación del sistema educativo. Curso 2003-2004. (Madrid, Subdirección General de Información y Publicaciones).

Consejo Escolar del Estado (2008): Informe sobre el estado y situación del sistema educativo. Curso 20062007. (Madrid, Subdirección General de Información y Publicaciones).

Consejo Escolar del Estado (2009): Informe sobre el estado y situación del sistema educativo. Curso 2007-2008. Propuestas de Mejora. (Madrid, Subdirección General de Información y Publicaciones).

Consejo Escolar del Estado (2010): Informe sobre el estado y situación del sistema educativo. Curso 2008-2009. Propuestas de Mejora. (Madrid, Subdirección General de Información y Publicaciones).

Villa, A. (2009): Autonomía institucional de los centros educativos: Presupuestos, organización y estrategias. (Universidad de Deusto).

\section{Referencias normativas}

Ley Orgánica 2/2006, de 3 de mayo, de Educación.

Ley Orgánica 8/2013 de Mejora de la Calidad Educativa.

Ley 30/1992, de 26 de noviembre, de Régimen Jurídico de las Administraciones Públicas y del Procedimiento Administrativo Común.

Ley 4/1999, de 13 de enero, de modificación de la Ley 30/1992, de 26 de noviembre, de Régimen Jurídico de las Administraciones Públicas y del Procedimiento Administrativo Común.

Real Decreto 1398/1993, de 4 de agosto, por el que se aprueba el reglamento del procedimiento para el ejercicio de la potestad sancionadora (RPPS).

Real Decreto 732/1995, de 5 de mayo, por el que se establecen los derechos y deberes de los alumnos y las normas de convivencia en los centros.

Real Decreto 83/1996, de 26 de enero, por el que se aprueba el reglamento orgánico de los institutos de educación secundaria.

Convención relativa a la lucha contra las discriminaciones en las esferas de la enseñanza. París, 14 de diciembre de 1960.

UNESCO: Convención de la UNESCO relativa a la lucha contra las discriminaciones en la esfera de la enseñanza, hecha en París el 14 de diciembre de 1960

\section{Referencias jurisprudenciales}

Tribunal Supremo (2003) STS $n^{\circ} 1.163 / 2003$ de 9/12/2003. Disponible en: http://www.codigo-civil.org/ archivado/:p=352 (consultado 15.IX.2009).

Tribunal Constitucional (1983) STC 77/1983, de 3 de octubre. Disponible en: http://vlex.com/vid/potestad-sancionadora-administracion-176571(consultado 15.IX.2009). 